\title{
A New Architectural Design of Elevated Small Group Automated Rapid Transit
}

\author{
Hugh Chapman and Mary Chapman \\ SkyCabs International Ltd. \\ Avishai (Avi) Ceder \\ University of Auckland
}

\begin{abstract}
Due to increased motorcar popularity, public transport use has declined while congestion costs billions in wasted time, fuel, accidents, air and water pollution. Proposed passenger transport projects have been cancelled in major cities, and completed projects have not attracted the private motorist. This study investigates reasons for this. As cities grow vertically and horizontally, they form three-dimensional mazes requiring special transport design solutions that enhance the city. Congestion can be alleviated by transferring passenger transport onto elevated solutions such as the presented Elevated Small Group Automated Rapid Transit (ESGART) SkyCabs system, which straddles the gap between Group Rapid Transit (GRT) and Personal Rapid Transit (PRT). This two-way monobeam is detailed, including ease of building through cities and low construction cost. Architectural and engineering aspects of eight-seater cabs, cab frequency, stations, and lines are described. This study also explores connectivity on two example lines in Auckland, New Zealand, within a SkyCabs network and to other modes of transport. Quantitative and qualitative attributes are considered. The result is a rapid transport system that is affordable
\end{abstract}


and attractive enough to draw significant numbers of auto users reducing congestion and $\mathrm{CO} 2$ emissions.

\section{Introduction}

As a consequence of increased motorcar popularity, public transport use has declined such that traffic congestion on our roads costs billions in wasted time, fuel, accidents, air and water pollution (Laird et al. 2001) Cities such as London, New York, Seattle, Chennai, Sydney, Melbourne, and Auckland have, in the last five years, delayed or abandoned planned rail, light rail, or monorail routes because of seemingly unjustifiable costs or costs well beyond budget.

\section{Objectives}

The objectives of this work are four-fold: (i) review briefly the interaction between city growth, public transport, and traffic congestion; (ii) propose a new passengertransport mode solution to reduce congestion; (iii) describe the new solution in detail and compare it to traditional forms of public transport; and (iv) perform connectivity analysis of the new solution using qualitative and quantitative attributes. The final objective aims at preparing the ground for the construction of a demonstration track as part of a pilot study of the new passenger-transport mode solution.

\section{Literature}

Several publications present an overview of new technologies in public transport. In a very comprehensive review of advanced transit systems, the U.S. Department of Transportation (Federal Transit Administration 2000) divides these systems into five groups. The first group consists of fleet-management systems, which include automatic vehicle location, public-transport operations software, communication systems, geographical information systems, automatic passenger counters, and systems for traffic priority. The other groups are traveler-information systems, electronic payment systems, systems for demand management, and intelligent public-transport vehicles. The discussion of each group contains a description of the technology, its benefits, a review of the state of the art and existing systems, and examples of application.

In a separate publication, the U.S. Department of Transportation (Federal Transit Administration 2006) identifies and quantifies the benefits derived from cur- 
rent applications of the advanced systems described in the previous publication (Federal Transit Administration 2000). A very detailed discussion of the various technologies addresses their benefits and costs, including monetary values based on actual experience. Applications of fixed bus routes, demand-responsive public transport, and various rail types are presented.

Blythe et al. (2000) presents an overview of intelligent transportation system (ITS) applications on public transport. The authors identify specific advantages that ITS can offer public transport in terms of travel-demand management, infrastructure management, vehicle management, information provision, and multi-modal ticketing.

The idea of intelligent public vehicles for private use has been discussed in the literature for a decade, but some small-scale cases of implementation have induced a new debate over practical issues. Anderson (2000) reviews the rationale for Personal Rapid Transit (PRT) and the process needed to develop it. Glazebrook and Subramania (1997) offer a detailed discussion of PRT, which is based on a concept similar to PRT.

\section{City Growth and Transport}

Urban expansion occurs in two ways. Easiest and lowest-cost expansion is spreading into newly available areas further from the city center. Closer to the central business district (CBD), expansion and development are more difficult and expensive. Vertical growth with ever taller buildings and higher occupancies in the CBD create a three-dimensional maze.

\section{Global Factors Affecting Travel Demand and Service Provision}

Global factors affecting travel demand and service provision (TranSystems et al. 2006) are summarized in the New Zealand (NZ) context:

- City/land development features and patterns such as geographic, topographic, ecological, zoning, density considerations.

- Population characteristics in zones, age distribution, activity-related travel.

- General and individual economic situation, household income, asset ownership.

- Features of travel mode, mode choice due to attractiveness and convenience.

- City/government intervention via regulation/assistance via subsidies. 


\section{Transport Difficulties with Buses and Traditional and Light Rail in the City}

Providing passenger transport from the outer edges of the city with their own "hubs" but with very low population densities involves long trips by buses into the central areas along increasingly congested roads.

The use of exclusive bus lanes near the central city to overcome the disadvantage of multiple stops and slow trips has to be regarded as a problem. While allowing faster bus trips, an exclusive bus lane takes a minimum 1,800 to 2,000 passengers/ hr auto users off the road. With 40-seater buses, up to 50 full buses per hour, one every 1.2 minutes, are required just to equal the lost capacity. A bus with 80 passengers gives a frequency of 2.4 minutes. Both are in the congestion-causing frequency (Nielsen et al. 2007). Buses alone on bus lanes do not seem to increase throughput of the roads.

Traditional rail services from the outer edges need exclusive rail corridors through the developed city, of necessity, do one or more of the following:

- Take over existing road space competing directly with cars and causing further congestion at intersections.

- Take land currently developed with housing and commercial land to provide the exclusive way (this still necessitates crossings at all roads at right angles)

- Raise the rail line above roads.

- Build tunneling underground with underground connections to the city above.

Rail lines are continually proposed to be placed directly along the simplest route, severing communities on either side. Any use involving crossing the rail lines is restricted, and accidents increase.

Light rail line costs are reduced by use of the roadway at the expense of previous use of the road. If light rail is to provide a service to attract auto users, as all new rail systems are expected to do, they need to be frequent and have a high operating speed. These two requirements cause a direct conflict with autos and pedestrians in any sharing of the road.

\section{Time Frames Travel Patterns and Proposed Rail Expenditure}

Congestion in cities normally shows up with the movement to the places of employment during 7:00 AM to 9:00 AM peak travel times at the start of business and the opening of schools and is at its worst usually in the CBD. Afternoon and evening peaks follow (Auckland Transport Models 1996). 
In Auckland, the major morning peak traffic is heading to the CBD from approximately eight directions, as shown in Figure 1 . The existing rail covers only two directions-the South and the West. As trains are full in peak hours, an expenditure of $\$ 3.9$ billion (NZ\$) currently is proposed to increase trains from 4 per hour to 6 per hour or at 10 -minute intervals. Using 600 or 800 passengers/train, this could allow an increase of 1,200 to 1,600 passengers/hr. Even if allowing three directions of rail service, this will lead to a total of 3,600 to 4,800 passengers/hr extra into the city for the capital expenditure of $\$ 3.9$ billion, or minimum $\$ 812,500$ investment per new passenger. Figure 1 also demonstrates the new network of the proposed solution of this work.

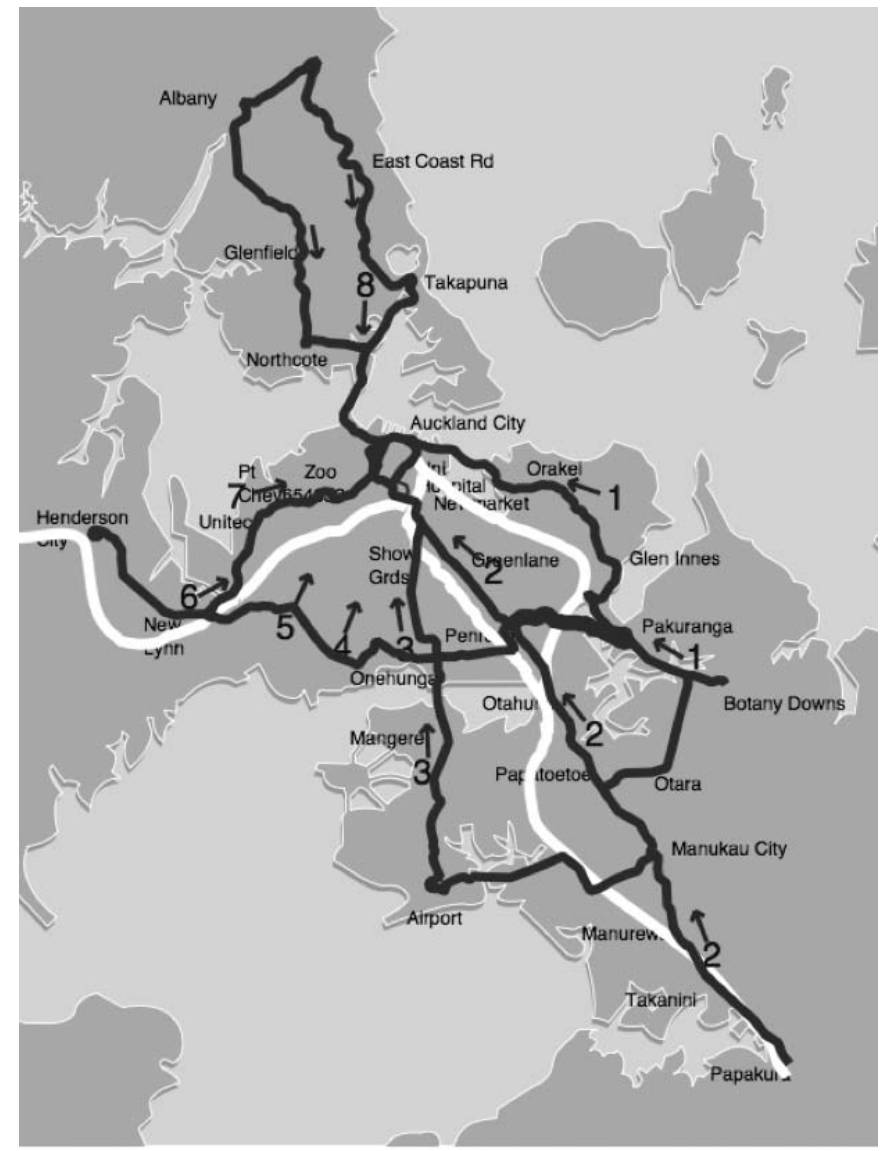

SkyCabs Graphs

Figure 1. Existing rail corridor (white) stations at $2086 \mathrm{~m}$ and proposed SkyCabs passenger-transport solution (black) stations at $750 \mathrm{~m}$ 


\section{Reducing Traffic Congestion}

There are two ways of achieving the reduction of congestion, and the two ways are best used together:

1. Using roads in a better manner than at present to facilitate peak traffic movement.

2. Improving passenger transport and its coverage so the auto user finds a better solution that does not use the present congested roadways.

The question then arises as to how to provide this attractive passenger transport without destroying the existing transport that has initiated and supported the life of the city.

\section{Architectural Approach}

During the last two centuries, except for the motor car, new means of urban transport have been designed on the mega structure philosophy. Many traditional transport systems, such as trains and monorails, need large stations and have large vehicles on the basis that they are cheaper to run if passengers are allowed to accumulate at stations so fewer vehicles are operated.

Architects design many different types of buildings from small to monumentaleducational facilities to inspire the young, office and commercial complexes, and enduring mega structures that dazzle viewers with art galleries, theatres, recreational facilities and sport stadiums. In the 21st century, the architect's approach to transport design has to be to design for the individual passenger. He/she needs a seat as soon as possible for a trip with as few stops as is reasonably possible and is as short as is reasonably possible.

\section{Where to Place the Transport Expansion}

The legally-defined road and the space above it are dedicated to transport. The space above the road is generally available for services with elevated components such as trolley buses, light rail, and monorail. There are fairly well reported capital costs when considering traditional rail and monorails. Bangkok's elevated rail with massive structures has been in financial difficulty three times. Indonesia tried several times to build a traditional monorail, but the cost has thwarted them so far. Seattle planned for a $23 \mathrm{~km}$ traditional monorail but found in 2005 that the US\$2.1 billion cost was too high and that the system would take over whole blocks of the city to turn a corner (Seattle Monorail Project 2003). 
The space under the road has been generally dominated by services and is available at a high cost. Few cities have found they can justify the funds for underground transport.

Analysis of the three-dimensional urban fabric shows that there is scope for an elevated transport system that has a relatively small structure and is able to carry considerable numbers of passengers at speeds better than the auto through a small, restricted envelope that can fit happily in the three-dimensional street context.

Analysis of all modes of road traffic in the city (Auckland Transport Models 1996) shows that the greatest pressure from congestion is normally on arterial roads leading to and from the CBD or major centers. The vehicles on such an elevated transport system need to be small and able to collect passengers requiring similar destinations traveling along such a main route (Bishop and Mole, 2001). These small vehicles also would need to be frequent to provide useful capacity, require far fewer stops because of their lower number of passengers, and have a speed close to or better than autos. Then, the individual passenger's traveling requirements could be met.

\section{New Transport Systems}

New systems have been developed over the last 10 to 20 years to improve urban passenger transport and reduce congestion. Many are still in the concept stage.

\section{Personal Rapid Transit (PRT)}

PRT focuses on totally personal trips for passengers. With the vast majority of passengers traveling alone, this necessitates many small vehicles. The smallness of the vehicle, the low number of passengers (1-4), and the short wheelbase restricting its speed, limit PRT in answering current urban needs. Hourly volume at three-second intervals, ranging from 1,200 single passengers/hr to around 1,700 passengers/hr, is below the capacity of a motorway lane. The small wheelbase restricts speed to around $30-40 \mathrm{~km} / \mathrm{hr}$, only slightly better than cars on a semi-congested motorway. However, elevated PRT can provide an additional transport option without the loss of existing road capacity on the ground, in the direction of the track. PRT has the advantage of not needing a timetable as long as there are sufficient vehicles available to answer the demand.

Austrans, although a nine- seater, is considered a PRT system by inventor Arthur Bishop. Taxi 2000, designed by Anderson USA (2000), and ULTra from Cardiff, UK, 
are examples of PRT. Both use electric four-seater vehicles and run on rubber tires. All three require either two tracks or double-width tracks to achieve travel in opposite directions. Austrans had a 500-meter demonstration track in Sydney. Taxi 2000's demonstration still operates on a dedicated guideway at 2.5 seconds frequency. ULTra completed an inter-terminal connection at Heathrow Airport in 2009.

An increasing number of cities are investigating elevated passenger transport. For the European Commission's (EC) Key Action "City of Tomorrow," short PRT systems were examined by the Evaluation and Demonstration of Innovative City Transport (EDICT) team in five urban environments: Huddinge in Sweden, Ciampino in Italy, Eindhoven and Almelo in the Netherlands, and Cardiff in the UK. This three-year study found high user acceptance and strong support from stakeholders, but both the Cardiff and Eindhoven projects were hindered by political problems (European Commission 2004).

\section{Small Group Rapid Transit}

The next largest passenger transport system is the Elevated, Small Group, Automated, Rapid, Transit (ESGART) system SkyCabs, designed and patented in New Zealand.

SkyCabs is an elevated two-way monobeam carrying light eight-seater cabs on tracks on each side of the beam, available on demand, providing fast, pollutionfree, unimpeded travel above the footpath with panoramic views of the city. It is a collector system distinct from PRT, with space for eight standing passengers per cab. The longer vehicle length facilitates design speeds up to $80 \mathrm{~km} / \mathrm{h}$ and a $60 \mathrm{~km} /$ hr average operating speed, considerably faster than PRT and light rail. SkyCabs is illustrated in Figure 2.

SkyCabs is an automated electric system. Safety performances of established driverless systems have been reported to be excellent, better than manual systems (Fabian 2004). SkyCabs uses similar high frequencies to PRT systems and provides vehicles smaller than the buses and trains of Group Rapid Transit systems and thus gains advantages over both.

\section{Capacity}

A single two-way SkyCabs line with eight-seater cabs and frequency of up to six seconds between vehicles gives a capacity of 4,800 passengers per hour. Therefore, the single two-way line can match the capacity of a four-lane motorway and, with the additional eight standing passengers, i.e., 9,000+ passengers/hr, that of an eightlane motorway. 


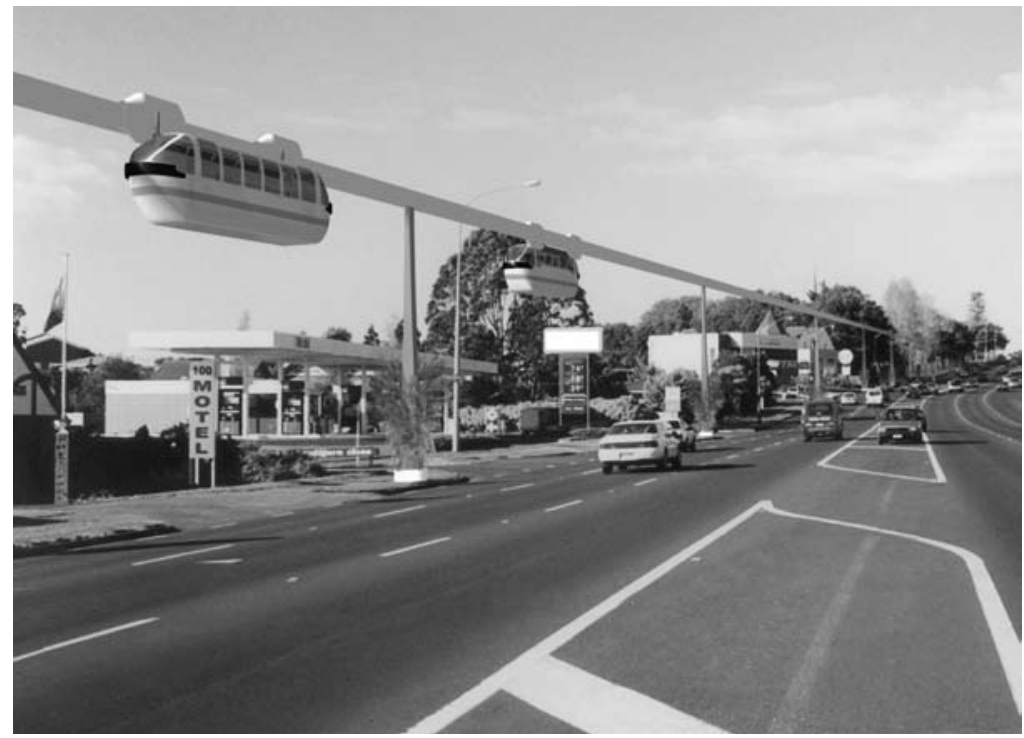

\section{Figure 2. Proposed small group rapid transit (SkyCabs) vehicle in simulated environment}

\section{Stations}

Off-line stations in both directions provide the key to SkyCabs' capacity and operating speed. These switched stations allow stopping cabs to go off the main line into the station to one of four ports to unload or load passengers. The four ports, with two separate access and rejoin tracks, enable a four-port station to handle the full capacity of the line, ensuring the line is kept clear for thru traffic. Two of the four ports can be used at night or in off-peak times for parking of cabs. The elevation of the SkyCabs track allows unobstructed passage for the cabs but requires vertical connection with fast lifts for passengers from ground level.

There are very convenient positions for stations above or within car parking areas and shopping and commercial centers. Placing stations at or within existing centers provides an urban planning tool for increasing density by adding to single level centers. Stations on the second floor increase the pedestrian count and add further value.

\section{Guideway}

Architecturally, SkyCabs can blend into the street fabric with some changes in street lighting and some services in the footpath bypassed, straddled, or rearranged. The small, light eight-seater plus eight standing cabs require about onetenth the concrete compared to guideways carrying heavy traditional monorails, 
resulting in much lower capital cost. The slim SkyCabs guideway can turn street corners and is light enough to go on bridges. Guideway on the north side of eastwest roads allows for any shadow from SkyCabs to be cast onto the street. With north-south roads, either side can be used, as any shadow passes very quickly. For engineering, the varying state of the ground can be catered for by adding additional depth to the drilled "pole" foundation. A flat surface foundation may be used in some circumstances, but a 1.5 -meter diameter pile could provide the usual limit of the required surface area approximately every 30 meters. Allowing 5-6 meter clearance under the cabs, the track itself would be 8-9 meters above the footpath.

In some cities, the visual impact of the guideway may be raised. Stakeholders living along a line may need to choose between quiet SkyCabs above the footpath out of sight and a bus lane either replacing parking outside their residence or carving off the front of their property, with noisy buses emitting $\mathrm{CO} 2$ and small particulates closer to their living and sleeping areas. In the European community report (2004) PRT study, reduction in car traffic and, hence, in air pollutants were valued highly. Visual impact as a result of the elevated track was raised only in Cardiff and in historic areas of Huddinge.

\section{Service Frequency and Wait Times}

The SkyCabs system is a collector system with automated vehicles. Calculations show that while a waiting time of less than one minute would be normal in a city such as Auckland, four minutes would be the longest wait to allocate a vehicle with available capacity approaching the stop during very low demand times. Parked vehicles can be activated to ensure minimal waiting.

Buses need timetables until six-minute interval is reached. As headway decreases from four minutes, traffic congestion and environmental pollution increase; this is shown in Figure 3.

Figure 3 shows the considerable difference between the service frequency possible with a SkyCabs system compared to buses and light rail. Waiting is similar to that of a lift. SkyCabs operate above the road space, so it does not cause congestion even at less than one minute headway or a 30 -second waiting time. 


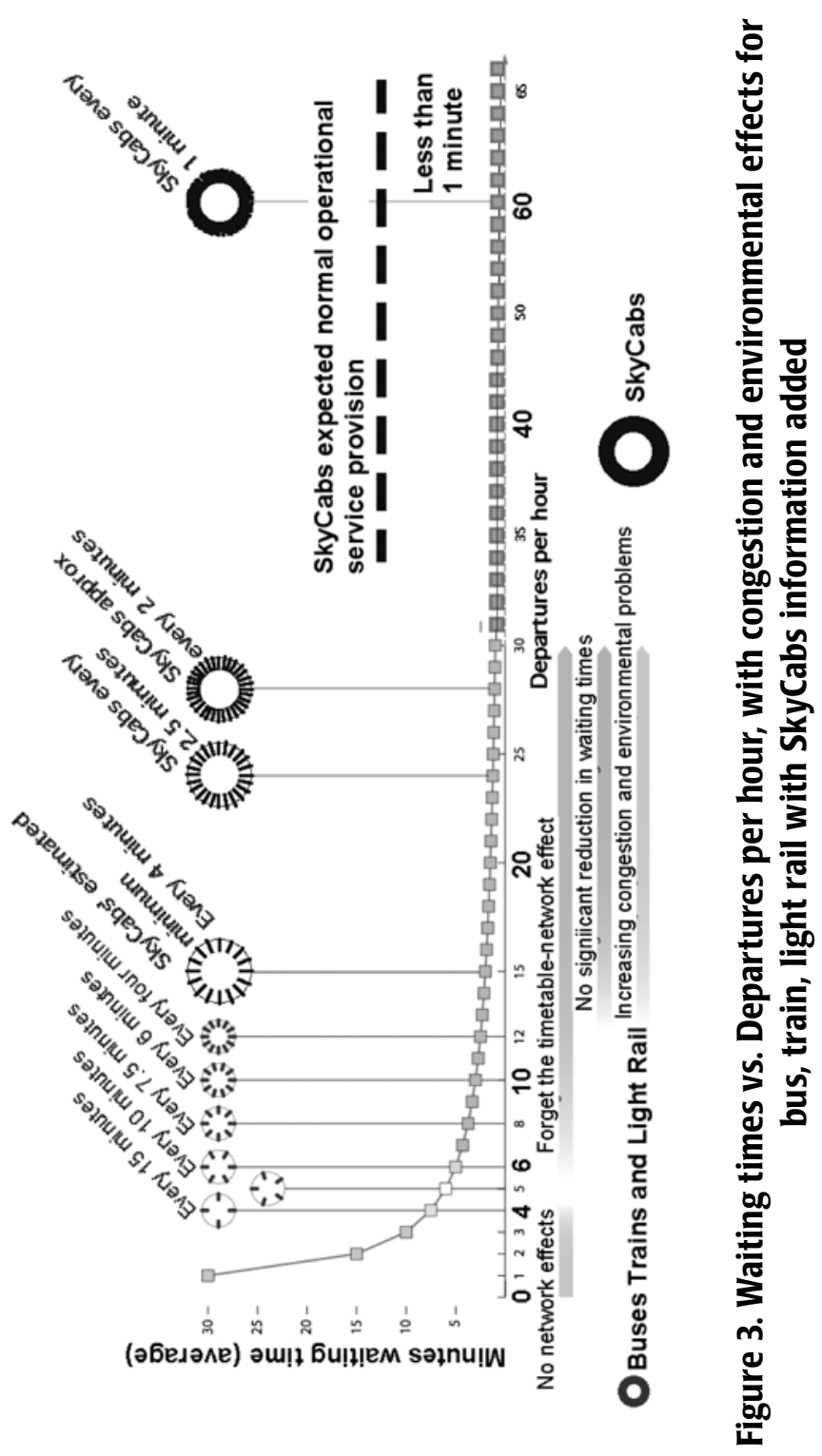




\section{Operating Speed}

Monorails, rail, and light rail cover the larger vehicle capacity systems. Large vehicles necessitate multiple stops. The Seattle monorail bid showed the fastest traditional monorail technically able to complete the end-to-end trip in $\mathbf{4 5}$ minutes or, at an operating speed of $30 \mathrm{~km} / \mathrm{hr}$, a speed only slightly faster than cars (Seattle Monorail Project 2003).

After cars on a flowing motorway, SkyCabs offers the next fastest trip times, followed by cars on flowing arterial roads and heavy rail. PRT, light rail, and buses are only slightly faster than cars on congested roads. These results are similar to mode comparisons presented by Lowson (2003).

In Figure 4, bus and train times from MAXX (operator of GRT in Auckland), actual in July 2009, light rail times from Phoenix Light Rail in 2009, and car and SkyCabs estimates for comparable $18 \mathrm{~km}$ journeys have been plotted against operating speed of the relevant mode.

\section{Inter Mode Integration}

Most elevated SkyCabs stations can be positioned easily above or close to bus and rail stations. Beginning any journey with SkyCabs, the "on demand" service means that the waiting for a cab starts when the passenger swipes his/her card and indicates a destination or stop. This would give a transfer time of around one minute and a waiting time of around another minute.

\section{Energy Use and Environmental Effects}

SkyCabs cabs are all-electric, lightweight eight-seaters. PRT vehicles generally are electric and lightweight four-seaters. The European community report (2004) found that PRT uses considerably less energy per passenger-km than cars or even conventional public transport. Even allowing for pollution caused by the production of the electricity required to run them, there is a net saving in both energy and emissions compared with the modes that their passengers would use otherwise. Furthermore, the expected reduction in car traffic will lead to further reductions in $\mathrm{CO}_{2}$ emissions. Electric vehicles also are generally quieter than the alternative modes. Small vehicles can be run inside buildings, thus reducing visual intrusion or habitat destruction. The main issue of concern is when the system runs outside historic buildings or private residences (European Commission 2004). Concerns may be mitigated by sensitive architectural design. Figure 5 presents a comparison between the findings of the European Community Report (European Commission 2004) and SkyCabs estimated energy use. 


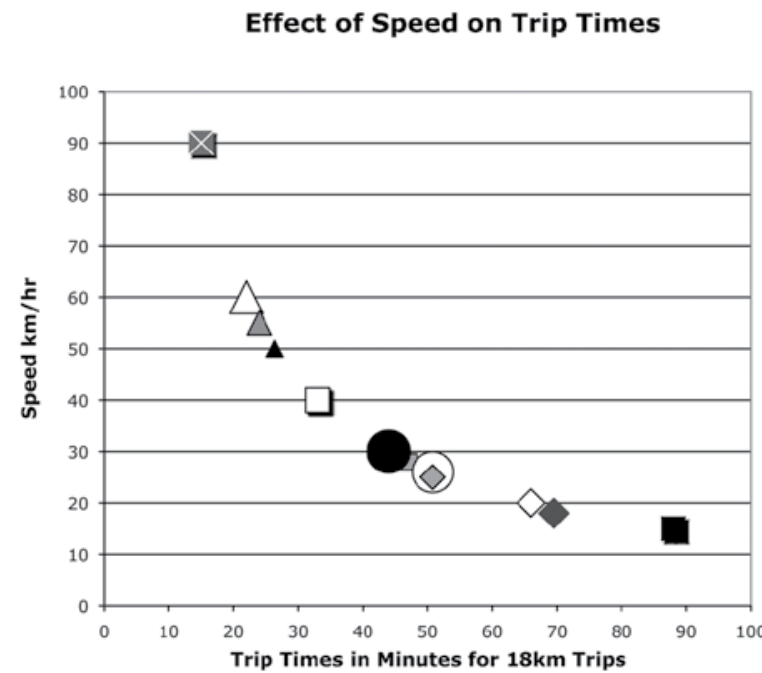

( Cars on flowing motorway $1.2 \mathrm{p} / \mathrm{car}$

$\triangle$ SKYCABS seated $-4800 \mathrm{p} / \mathrm{hr} /$ direction

$\Delta$ SKYCABS including standees $-9000 \mathrm{p} / \mathrm{hr} / \mathrm{d}$

A SKYCABS METROPOLIS - $19,000 \mathrm{p} / \mathrm{hr} / \mathrm{d}$

ㅁ Car on arterial road $1.2 \mathrm{p} / \mathrm{car}$

- Train Heavy rail - 6000p/hr/d

- - PRT 2 seated $=2400 \mathrm{p} / \mathrm{hr} / \mathrm{d}$

- - Light rail 600 seated and standing $6000 \mathrm{p} / \mathrm{hr} / \mathrm{d}$

- Bus 40 seated,part Busway/road opp peak flow

$\checkmark$ Bus 40 seated, part Busway, part road, peak flow

- Bus 40 seated on roads

- Cars congested on Motorway, $1.2 \mathrm{p} / \mathrm{car}$

Figure 4. Effect of different mode operating speeds on trip time

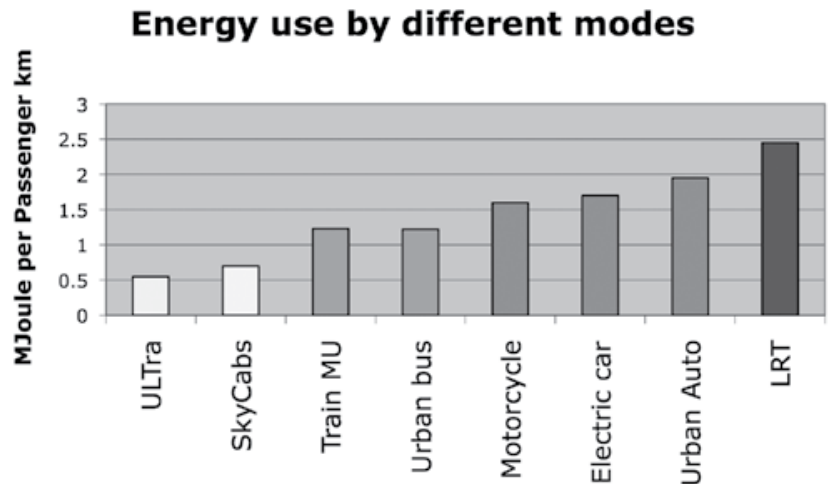

Source: European Community Final Report (2004)

Figure 5. Energy use by different modes plus estimate of SkyCab energy use/passenger $\mathbf{k m}$ 


\section{New Transport Systems/Modes in Auckland}

\section{Current Situation}

A two-lane road with parking on each side changed to clearways at peak hours has a total capacity of two working lanes in the direction of peak time flow. The present approach in Auckland is to change peak- time clearway/daytime parking along the road to a bus lane. With peak-time exclusive bus lanes, the total capacity in the direction of peak-time flow is one working lane plus bus lane capacity. This configuration can be equal only to the two working lanes when the bus lane use equals the car-carrying capacity of the one road lane. In reality, this takes many years to occur, while the remainder of the increasing number of displaced cars is backed up along the remaining one road lane or its side streets.

\section{Dominion Rd, Auckland}

This road has been converted into two lanes of general vehicles, one per direction, with a bus lane on each side. It is claimed that nearly half of the trips are public passenger transport trips along this route. This illustrates that this bus lane with buses at 12 per hour does not add to the throughput of passengers, its main reason for existence, but is only close to the capacity of a general vehicle lane.

\section{Onewa Rd, North Shore, Auckland}

One of the two lanes connecting Onewa Rd to the motorway was specified as a transit lane for high occupancy vehicles (T3). The initial 45 percent of peak-time commuters using carpooling and buses increased to 55 percent, but congestion reportedly doubled for the 45 percent remaining car users. By 2008, carpooling increased from 9 to 28 percent, while bus use increased from 36 to 40 percent. The T3 lane accounts for only 27 percent of all vehicles using the two inbound lanes, giving an average of 2.7 people per vehicle across both lanes compared to overall average of 1.1 people per vehicle for car only travel in Auckland (Macbeth and Fowler 2008). The short length $(1 \mathrm{~km})$ of the T3 lane shunts buses and HOV vehicles to the front of the queue, encouraging carpooling and thus achieving a degree of increase in throughput. There is restriction on the motorway after Onewa Rd, and the congestion experienced still needs some solution to ease traffic in the car lane on Onewa Rd.

\section{New Transport for Future Growth}

What else could be done on these two routes to future proof for population growth and to increase capacity significantly and at what cost? PRT, light rail or SkyCabs line could be installed at varying effects and costs per mode. Figure 6 compares the different modes. 


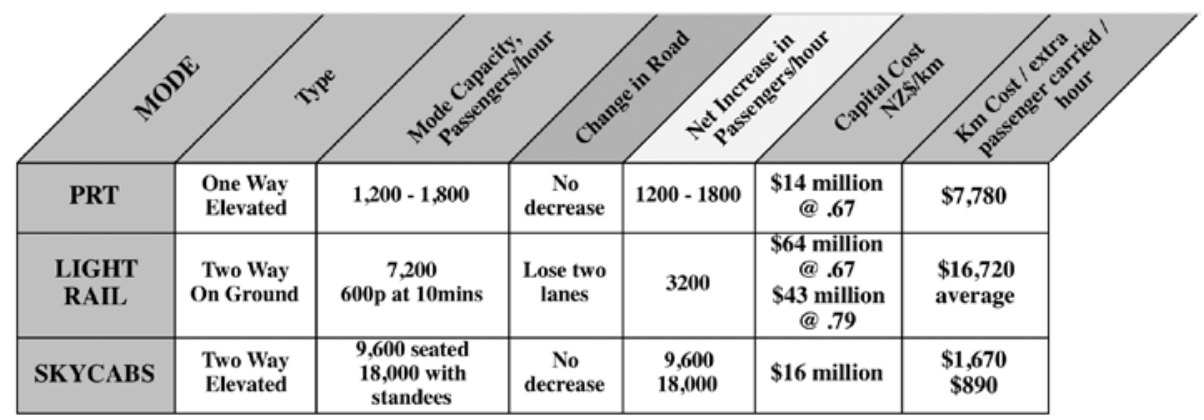

Figure 6. Mode effect on road and on capital cost $/ \mathrm{km}$ per extra traveler per hour

The costs associated with the three modes of Figure 6 are as follows:

- PRT cost is US\$9.4 million/km, adjusted from Ultra (www.ultraprt.com, 2010).

- Light rail average cost is US\$43 million/ $\mathrm{km}$. (Cox 2002)

- Phoenix Light Rail as built in 2008, US\$43.5 million/km (www.azcentral. com /news/articles/2008/12/09), converted at 0.67 to NZ\$64 million.

- City of Sydney Light Rail Extension A\$34.4 million/km (Price Waterhouse Cooper 2006), converted at 0.79 to NZ\$43 million.

- SkyCabs construction cost estimate of NZ\$16 million $/ \mathrm{km}$ would convert to approximately US\$14 million/ $\mathbf{k m}$ overseas, including stations at $750 \mathrm{~m}$ centers. SkyCabs figures are based on design parameters and construction cost estimates from consultants and manufacturers.

In Figure 6, three options are compared for providing greater capacity on either of the two roads examined. The light rail option would entail the loss of two road lanes. Allowing 2,000 travelers per hour per flowing arterial lane, the extra passengers carried reduce to 3,200. The capital cost related to this added capacity is an average $\$ 16,720$ per extra passenger per hour. Both PRT and ESGART (SkyCabs) show considerably lower capital cost per extra passenger, with PRT at less than 50 percent of the light rail cost and SkyCabs only 10 percent of the light rail cost per extra passenger per hour. If PRT travelers are prepared to accept four passengers in one vehicle and potentially detour for variable destinations, the resulting higher capacity would reduce the capital cost per extra passenger carried per hour, although volume carried in an hour may reduce due to longer routes traveled. For SkyCabs with fixed routes, an even lower potential capital cost of $\$ 890$ per extra 
peak time passenger per hour is achieved when eight standees are added to the eight seated passengers. There is considerable advantage provided by the introduction of these new forms of transport.

A further comparison between SkyCabs and other modes concerning different characteristics appears in Table 1. Most characteristics and values for other modes are from Viability of Personal Rapid Transit in New Jersey (2007). The SkyCabs figures are from design parameters and consultant and manufacturer estimates.

\section{Table 1. SkyCab Compared to Other Passenger Travel Modes}

\begin{tabular}{|c|c|c|c|c|c|}
\hline & $\begin{array}{c}\text { Part Busway } \\
\text { and Part } \\
\text { Buslane }\end{array}$ & Light Rail & $\begin{array}{l}\text { Standard } \\
\text { Monorail }\end{array}$ & $\begin{array}{l}\text { PRT (Personal } \\
\text { Rapid Transit) }\end{array}$ & $\begin{array}{l}\text { SkyCabs } \\
\text { (Esgart) }\end{array}$ \\
\hline $\begin{array}{l}\text { Cost per km } \\
\text { of 2-way track }\end{array}$ & $\begin{array}{l}\text { US\$15 - \$25 } \\
\text { million }\end{array}$ & $\begin{array}{l}\text { US\$31 - } \\
\$ 43.5 \text { million }\end{array}$ & $\begin{array}{l}\text { Varies to US } \\
\$ 62 \text { million }\end{array}$ & $\begin{array}{l}\text { US\$18.6 - \$31 } \\
\text { million }\end{array}$ & $\begin{array}{l}\text { Below US\$20 } \\
\text { million }\end{array}$ \\
\hline $\begin{array}{l}\text { Cost of } \\
\text { stations and } \\
\text { vehicles }\end{array}$ & Not included & Included & Included & Included & Included \\
\hline $\begin{array}{l}\text { Distance } \\
\text { between } \\
\text { stations }\end{array}$ & $\begin{array}{l}200-2000 \\
\text { meters off- } \\
\text { lane }\end{array}$ & $\begin{array}{l}200-500 \\
\text { meters in- } \\
\text { line }\end{array}$ & $\begin{array}{l}1000-1500 \\
\text { meters in-line }\end{array}$ & $\begin{array}{l}500-1000 \\
\text { meters off-line }\end{array}$ & $\begin{array}{l}750 \text { meters } \\
\text { off-line }\end{array}$ \\
\hline $\begin{array}{l}\text { Speed of } \\
\text { construction }\end{array}$ & $\begin{array}{l}\text { Two opposing } \\
\text { "on ground" } \\
\text { lanes by } \\
\text { motorway }\end{array}$ & $\begin{array}{l}\text { Two "on } \\
\text { ground" } \\
\text { tracks in } \\
\text { road }\end{array}$ & $\begin{array}{l}\text { Two large } \\
\text { elevated tracks } \\
\text { required }\end{array}$ & $\begin{array}{l}\text { Two small } \\
\text { elevated tracks } \\
\text { required }\end{array}$ & $\begin{array}{l}\text { Single small } \\
\text { two-way } \\
\text { elevated beam } \\
\text { over footpath }\end{array}$ \\
\hline $\begin{array}{l}\text { Average speed } \\
\text { of travel }\end{array}$ & $30 \mathrm{~km} / \mathrm{hr}$ & $24 \mathrm{~km} / \mathrm{hr}$ & $42 \mathrm{~km} / \mathrm{hr}$ & $42 \mathrm{~km} / \mathrm{hr}$ & $60 \mathrm{~km} / \mathrm{hr}$ \\
\hline $\begin{array}{l}\text { Capacity } \\
\text { seated }\end{array}$ & $\begin{array}{l}2,400 \text { people/ } \\
\text { hr/direction } \\
\text { at } 1 \text { min } \\
\text { intervals }\end{array}$ & $\begin{array}{l}3,000 \\
\text { people/hr/ } \\
\text { direction }\end{array}$ & $\begin{array}{l}\text { 3,000 people/ } \\
\mathrm{hr} / \text { direction }\end{array}$ & $\begin{array}{l}1,200-4,800 \\
\text { people/hr/ } \\
\text { direction }\end{array}$ & $\begin{array}{l}\text { 4,800 people/ } \\
\text { hr/direction }\end{array}$ \\
\hline $\begin{array}{l}\text { Capacity } \\
\text { seated and } \\
\text { standing }\end{array}$ & $\begin{array}{l}\text { Up to } 7,200 / \\
\text { hr crammed } \\
\text { at } 1 \text { minute } \\
\text { intervals }\end{array}$ & $\begin{array}{l}6,000 / \mathrm{hr} \text { up } \\
\text { to } 9,000 / \mathrm{hr} \\
\text { crammed }\end{array}$ & $\begin{array}{l}6,000 / \mathrm{hr} \text {, up } \\
\text { to } 9,000 / \mathrm{hr} \\
\text { crammed }\end{array}$ & $\begin{array}{l}1,200-4,800 \\
\text { people/hr/ } \\
\text { direction }\end{array}$ & $\begin{array}{l}9,000 \text { people/ } \\
\text { hr/direction }\end{array}$ \\
\hline $\begin{array}{l}\text { Peak-time } \\
\text { service }\end{array}$ & $\begin{array}{l}2-10 \mathrm{~min} \\
(6-30 \mathrm{veh} / \mathrm{hr})\end{array}$ & $\begin{array}{l}\text { 2-10 } \mathrm{min} \\
(6-30 \mathrm{veh} / \mathrm{hr})\end{array}$ & $\begin{array}{l}4-6 \text { min wait } \\
\text { (10-15 veh/hr) }\end{array}$ & $\begin{array}{l}\text { Time to ar- } \\
\text { range } \\
\text { passengers }\end{array}$ & $\begin{array}{l}30 \text { secs to } \max \\
4 \mathrm{~min}(15-120 \\
\text { veh/hr) }\end{array}$ \\
\hline $\begin{array}{l}\text { Off-peak } \\
\text { service }\end{array}$ & $\begin{array}{l}15-30 \text { min } \\
\text { wait ( } 2-4 \text { veh/ } \\
\text { hr) }\end{array}$ & $\begin{array}{l}12 \mathrm{~min} \text { wait } \\
(5 \mathrm{veh} / \mathrm{hr} \text { ) }\end{array}$ & $\begin{array}{l}12 \mathrm{~min} \text { wait } \\
(5 \mathrm{veh} / \mathrm{hr})\end{array}$ & No waiting & $\begin{array}{l}30 \text { secs to } \max \\
4 \mathrm{~min}(15-120 \\
\mathrm{veh} / \mathrm{hr})\end{array}$ \\
\hline
\end{tabular}


Fiscally responsible choice of public transport modes should be governed by the selection of the most economical method of adding capacity to arterial roads to ensure congestion is significantly reduced.

\section{A Well Connected Path}

Besides SkyCabs being all-electric, non-polluting, and very quiet with soft wheels, further attributes are required for auto users to choose alternative public transport. One possible definition (Ceder 2007) of a prudent, well-connected transit path is this:

An advanced, attractive transit system that operates reliably and relatively rapidly, with smooth (ease of) synchronized transfers, part of the door-todoor passenger chain.

Interpretation of each component of this definition as it relates to SkyCabs includes:

\section{Attractiveness}

- Clearly visible SkyCabs stations with convenient shops, protected from elements.

- Easy route selection with map directory and electronic display.

- Easy fare payment with smart card.

- Kind to the environment, emission-free electric cabs.

- Comfortable airline-quality seats in cab.

- Panoramic elevated views from SkyCabs windows along the route.

- Provision for wheelchair, pram, and bicycles, on-board entertainment in cabs.

Reliability

- Short waiting time, on demand SkyCabs service, small variance in journey times as elevated route avoids intersections, traffic lights, and general road congestion.

- Safe, automated computerized controls, built-in double redundancy where needed.

- Complies with ASCE Standards (American Society of Civil Engineers 2002) for automated people movers.

Rapidity

- Easy access/egress to and from vehicle, door opening three meters wide. 
- Fast travel at average $60 \mathrm{~km} / \mathrm{hr}$ operating speed, also express service available.

- Off line stations allow following traffic to bypass stationary cab.

Smoothness (ease)

- Approximate distance between off-line SkyCabs stations/stops is 750 meters.

- Fast lifts to transport platform, no timetables needed as service is on demand.

- Connects local communities otherwise bypassed or severed.

Synchronicity

- Can integrate with all other modes of transport via elevated stops.

- Cab allocation is computer controlled and demand responsive.

- On the SkyCabs network, one 1-4 minute transfer covers Greater Auckland suburbs.

Key areas of dissatisfaction with public transport were found to be timing, frequency, and destination (Bachels et al. 1999). Also, the need to transfer between routes generates a major cause of discomfort for transit users. Designing routes and schedules with a minimum amount of waiting time during a transfer may decrease the level of inconvenience. Many papers have been written from the 1970s to today about a variety of ways to design synchronized transit services. Improving transit connectivity is one of the most vital tasks in transit-operations planning (Ceder 2007).

\section{Connectivity Measures}

Eight quantitative attributes that can be measured to evaluate the quality of connectivity and three subjective qualitative attributes that can be survey-based are listed by Ceder (2007). The common denominator for all transit services are the following quality-of-connectivity attributes:

$\mathrm{e}_{1}=$ Average walking time (for a connection)

$\mathrm{e}_{2}=$ Variance of walking time

$\mathrm{e}_{3}=$ Average waiting time (for a connection)

$\mathrm{e}_{4}=$ Variance of waiting time

$\mathrm{e}_{5}=$ Average travel time (on a given transit mode and path)

$\mathrm{e}_{6}=$ Variance of travel time 


$$
\begin{aligned}
& \mathrm{e}_{7}=\text { Average scheduled headway } \\
& \mathrm{e}_{8}=\text { Variance of scheduled headway }
\end{aligned}
$$

These eight attributes, which can be measured, are termed quantitative attributes.

Other important attributes are not easily quantified and measured. Three of these include:

$e_{9}=$ Smoothness (ease)-of-transfer (on a given discrete scale)

$e_{10}=$ Availability of easy-to-observe and easy-to-use information channels (on a given discrete scale)

$\mathrm{e}_{11}=$ Overall intra- and inter-agency connectivity satisfaction (on a given discrete scale)

These hard-to-quantify attributes are termed qualitative attributes.

Different perceptions of these by different passengers are captured in the average weighting of each attribute. The weight of each attribute is survey-based and/or based on the results of a mode (path)-choice model. Measuring transit connectivity involves various parameters and components, as described by Ceder et al. (2009).

Adding up all connectivity component measures along given paths will give overall connectivity value for those paths so a comparison can be made among paths. Destinations can be evaluated for access-connectivity. Introducing average passenger numbers using the paths gives exposure-connectivity, and paths can be evaluated for people-access-connectivity. Comparisons considering passenger flow can be made among paths and destinations. In addition, Ceder (2007) described how weaknesses and bottlenecks of transit connectivity can be found and corrected.

\section{Connectivity of Some Bus and SkyCabs Paths}

\section{Inter-Route and Inter-Mode Path Comparison}

Two sets of origins and destinations were chosen for comparison:

(1) Origin O6: Browns Bay, North Shore; Destination D3: Onehunga, South Auckland

(2) Origin O8: Onehunga, South Auckland; Destination D1: CBD, Auckland. 
Some values of attributes were obtained from studies carried out at the Transport Research Centre, University of Auckland (Ceder et al. 2009). Several other paths and associated travel times were obtained from the MAXX Auckland website. For the SkyCabs connections on paths and for the Onehunga - CBD paths P5, $\mathrm{P} 6$, and P7, additional nomenclature is used for origin, destination, and arcs. Qualitative attributes $\mathrm{e}_{9^{\prime}}, \mathrm{e}_{10^{\prime}}$ and $\mathrm{e}_{11}$ have been excluded in calculating connectivity.

On Browns Bay to CBD paths, nomenclature for origins, destinations, hubs, and arcs follows that of Ceder et al. (2009). Table 2 and Figure 7 show the resultant path with best connectivity during the morning 7:00-9:00 AM peak.

\section{Table 2. Definitions and Path Description that Involves SkyCabs}

\begin{tabular}{|c|c|c|c|c|}
\hline Path & Origin & Destination & Arcs & Path Description \\
\hline P1 & O 6 & D 3 & A25+A10+A35 & Walk-wait-Public Bus-wait-Public Bus-wait-Public Bus-Onehunga \\
\hline P2 & O 6 & D 3 & A32+ASC1+ASC2 & Walk-wait-Public Bus-wait- SkyCabs -wait- SkyCabs -Onehunga \\
\hline P3 & O 6 & D 3 & A32+ASC3 & Walk-wait-Public Bus-wait- SkyCabsExpress -Onehunga \\
\hline P4 & O 6 & D 3 & ASC3 & Drop off-wait- SkyCabsExpress -Onehunga \\
\hline P5 & O 8 & D 1 & $\mathbf{A 3 3 + A 3 4}$ & Walk-wait-Public Bus-wait-Public Bus-Queen St \\
\hline P6 & O 8 & D 1 & A35 & Walk-wait-Public Bus-Queen St \\
\hline P7 & O 8 & D 1 & ASC2 & Walk-wait- SkyCabs -Queen St \\
\hline
\end{tabular}

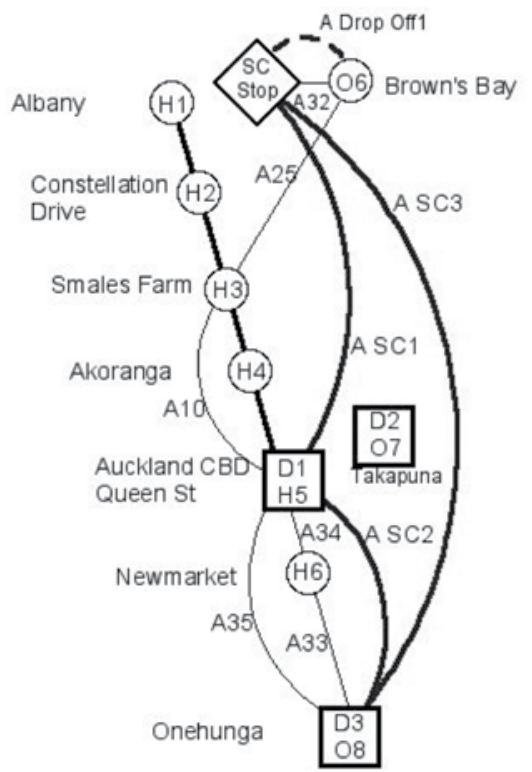

\begin{tabular}{|c|c|}
\hline \multicolumn{2}{|l|}{ KEY } \\
\hline & North Shore Busway \\
\hline (H2) & Hubs on Busway \\
\hline \begin{tabular}{|l|} 
D1 \\
H5 \\
\end{tabular} & $\begin{array}{l}\text { Destination } 1 \\
\text { Hub } 5\end{array}$ \\
\hline $\begin{array}{l}\mathrm{D} 2 \\
\mathrm{O} 7 \\
\end{array}$ & $\begin{array}{l}\text { Destination } 2 \\
\text { Origin } 7\end{array}$ \\
\hline$\overline{\mathrm{A} 25}$ & Arc 25 \\
\hline SC & SkyCabs \\
\hline A Drop Off & Car Drop Off and Ride \\
\hline 7 & SkyCabs Station \\
\hline & SkyCabs Arc \\
\hline
\end{tabular}

Figure 7. Schematic connectivity outline: Browns Bay to Onehunga, Onehunga to CBD 
Based on the analysis of connectivity measures (Ceder 2007 and Ceder et al. 2009), Figure 8 introduces a comparison between different linked transit modes. The bold curves are associated with SkyCabs, and the value of the Y-axis is a normalized value of the connectivity a per passenger/hour basis. The lower the normalized value, the better the connectivity. The best connectivity is shown on paths that are uni-modal SkyCabs paths. The superior connectivity of the paths involving SkyCabs is due to faster unimpeded travel on an elevated guideway, shorter waiting times, and headways due to high frequency and on-demand service.

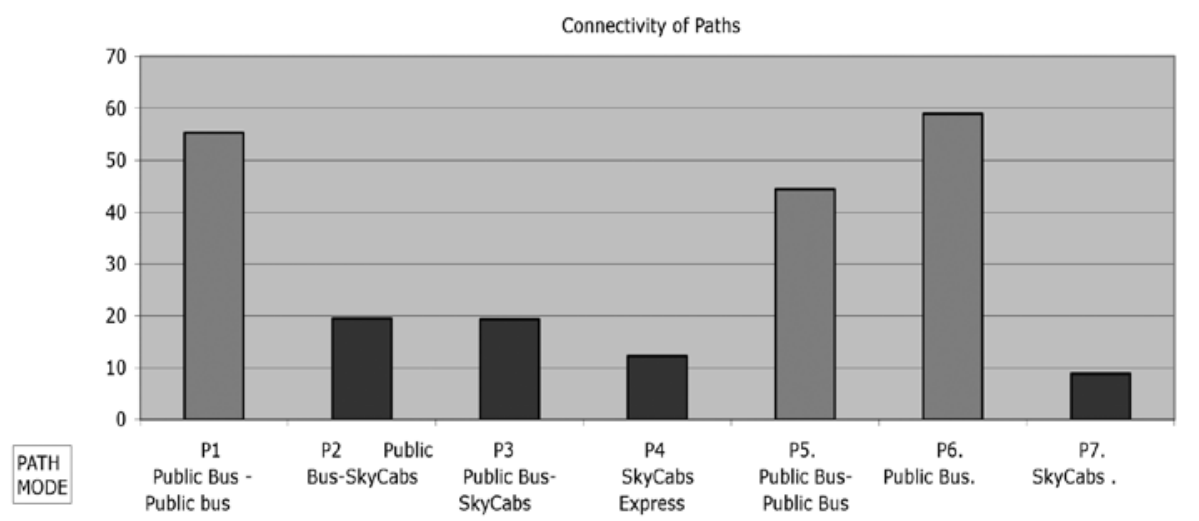

\section{Figure 8. Normalized connectivity of busway, SkyCabs, and combined mode paths}

Routes and schedules of superior connectivity with minimum amount of waiting time during a transfer are likely to decrease the level of inconvenience and discomfort for passengers and can be expected to encourage greater public transport use.

\section{Economic Effects of Congestion and Pollution}

As cars take longer and drive at a slower pace, engine inefficiencies increase dramatically. A car caught in traffic will operate at 400 percent less efficiency compared to operating at $60-80 \mathrm{~km} / \mathrm{hr}$ (Laird et al. 2001). Reduction of congestion that leads to reduced car travel times on city roads and motorways by 50 percent would reduce pollution by well over 50 percent through improved engine performance (Auckland Regional Council).

Auckland's local city councils together have a yearly budget of $\$ 2.3$ billion (Royal Commission on Auckland Governance 2009). Cost of congestion to Auckland city, 
industry, and residents has been estimated by various bodies, including SkyCabs, at $\$ 2$ billion per annum. Auckland's growth per capita in real GDP grew by only 1.1 percent per annum over the five years to 2003 against an NZ average growth of 2.3 percent p.a. (New Zealand Round Table 2006). If congestion and the $\$ 2$ billion congestion cost were removed, and all time saved was used productively, the increase in Auckland's GDP would be 4.2 percent p.a., and New Zealand's GDP would increase by 1.2 percent.

\section{Conclusion}

Significant reduction of congestion can improve economic performance and reduce pollution, both vital areas of concern for cities around the world. Congestion can be alleviated by transferring passenger transport onto elevated solutions such as the presented Elevated Small Group Automated Rapid Transit (ESGART) SkyCabs system, which straddles the gap between Group Rapid Transit (GRT) and Personal Rapid Transit (PRT). This two-way monobeam is detailed in this study, including ease of building through cities and low construction cost. Architectural and engineering aspects of eight-seater cabs, cab frequency, stations, and lines also are described. In addition, this study explores connectivity on two example lines in Auckland within a SkyCabs network and other modes of transport in which quantitative and qualitative attributes are considered.

The SkyCabs ESGART system could provide an attractive and affordable passenger transport solution to congestion problems. Initial connectivity comparison of the SkyCabs paths to comparable paths on the North Shore busway in Auckland is favorable, due to faster unimpeded travel on SkyCabs elevated guideway and shorter waiting times and headways. Further studies should be carried out for an extended SkyCabs network (see Figure 1). A short $\$ 5.5$ million demonstration track needs to be funded and built to confirm the technology and the estimated low capital and operating costs. Finally, new bold thinking is needed to make our cities economically productive.

\section{References}

American Society of Civil Engineers. 2002. Automated People Mover Standards, 1, 2, 3. Anderson, J.E. 2000. A review of the state of the art of personal rapid transit. Journal of Advanced Transportation 34: 3-29.

Auckland Regional Council (ARC). 1996. Auckland Transport Models Project. 
Bachels, M., P. Newman, and J. Kenworthy. 1999. Indications of urban transport efficiencies in NZ main cities. Study prepared for a number of New Zealand government bodies and published by the Institute for Science and Technology Policy, Murdoch University (contact ISTP at Murdoch University).

Bishop, A., and J. Mole. 2001. Automated rapid transit-What size vehicle is environmentally sustainable. Paper number 2001-01-3721, Environmental Sustainability Conference, Grax, Austria.

Blythe, P. T., Rackliff, T., Holland, R., and Madeean, J. 2000. ITS applications in public transport: Improving the service to the transport system user. Journal of Advanced Transportation 34: 325-345.

Ceder, A. 2007. Public Transit Planning and Operation: Theory, Modeling and Practice. Elsevier, Butterworth-Heinmann, Oxford, UK.

Ceder, A., Y. Le Net, and C. Coriat. 2009. Measuring public transport connectivity performance applied in Auckland. Transportation Research Record 1111: 138147.

Cox, W. Consultancy. 2002. Urban Transport Fact Book, FTA New Starts 1999, 2000.

European Commission DG Research. 2004. Evaluation and demonstration of innovative city transport, final report, project reference no. EVK4-CT- 2001-00058.

Fabian, L. 2004. The safety record of automated guide-way transit. A planner's guide to automated people movers. Trans.21, Transportation Systems for the Twenty-First Century, Boston, 2002.

Federal Transit Administration, U.S. Department of Transportation, Washington, D.C. 2000. Advanced Public Transportation Systems: The State of the Art. Transit Administration Report.

Federal Transit Administration, U.S. Department of Transportation, Washington, D.C. 2000. Benefits Assessment of Advanced Public Transportation System Technologies. Transit Administration Report.

Federal Transit Administration, U.S. Department of Transportation, Washington, DC. 2006. Advanced Public Transportation Systems: The State of the Art update 2006. Transit Administration Report.

Glazebrook, G., and S. Subramanian. 1997. Personal public transport in Australia: Developments and prospects. Journal of Public Transportation 3: 45-69. 
Laird, P., P. Newman, M. Bachels, and J. Kenworthy. 2001. Back on Track: Rethinking Transport Policy in Australia and New Zealand. Sydney, University of New South Wales Press.

Lowson, M. 2003. Service effectiveness of PRT vs. collective-corridor transport. Journal of Advanced Transportation 37(3): 231-341.

Macbeth, A., and M. Fowler. 2008. Transport network optimization. NZTA website.

New Zealand Round Table. 2006. Report.

Nielsen, G. (Institute of Transport Economics), and T. Lange (Civitas Group of Consultants), Oslo, Norway. 2007. Network design for public transport successTheory and examples 11. Thredbo Conference, Hamilton Island, Australia.

Price Waterhouse Cooper. 2006. City of Sydney Light rail extension, final analysis. Royal Commission on Auckland Governance. 2009. Report.

Seattle Monorail Project. 2003. Request for proposal and associated documents.

TranSystems Corp., Planner Coll., Inc., and Crikelair, T. Assoc. 2006. Elements needed to create high ridership transit systems: Interim guidebook. TCRP Report 32, Transportation Research Board, Washington, D.C.

Viability of Personal Rapid Transit in New Jersey. 2007. Report to Department of Transportation, Bureau of Research, as given to the Governor and the New Jersey State Legislature.

\section{About the Authors}

Hugh Chapman (Hugh@skycabs.co.nz) is a Registered Architect and CEO and Director of SkyCabs International Ltd. His practice specializes in residential, light industrial, and commercial work with emphasis on energy-efficient buildings. He has varied design interests, including body design for a low-cost three-wheeler car, a geodesic dome housing system suitable for mass production, design of reinforced concrete moulded building panels for cyclone prone areas, and a patented solar water heater. He has been involved in urban planning, making annual submissions to government select committees and local authorities on town planning, transport, and energy and is the concept originator and designer of the patented SkyCabs Elevated Small Group Automated Rapid Transport (ESGART) system, which can add the equivalent capacity of two motorway lanes in each direction to any road. 
He has liased with consultants, potential suppliers, manufacturers, financiers, and consortium partners and has been guest speaker at numerous organizations and conferences promoting the SkyCabs design.

MARY CHAPMAN (mary@skycabs.co.nz), BSc., DipBIA, is a past director of a family manufacturing business, responsible at various times for product design, production planning and monitoring, sales, and marketing as well as capital investment decisions, raw materials importing, and representing the company at industry meetings. Currently, she is Resources Manager at SkyCabs International Ltd, responsible for human, physical, and intellectual resources, and is involved in strategic and project planning and component and construction cost analysis and estimating.

Avishal (Avı) CeDer (a.ceder@auckland.ac.nz) is Professor and Chair in Transportation in the Department of Civil and Environmental Engineering and Director of the newly-established transportation research centre (TRC) at the University of Auckland in New Zealand. He had a long career at the Technion, where he was the Head of the Transportation Engineering and Geo-Information Department and was a visiting Professor twice at MIT, UC- Berkeley, and the Universities of Hong Kong and Tokyo. He was Chief Scientist at the Israel Ministry of Transport from 1994 to 1997 and the Israel delegate to the Transport Program of the European Community. He is a member of various international symposia and workshops (e.g., ISTTT, CASPT) and in 2007 published Public Transit Planning and Operation: Theory, Modelling and Practice by Elsevier, Oxford, UK, which was translated into Chinese by the Tsinghua Press in Beijing in June 2010. 